\title{
The pattern and challenges of infertility management in Lagos, Nigeria
}

\author{
*Adegbola $\mathrm{O}$, Akindele $\mathrm{MO}$ \\ Department of Obstetrics and Gynaecology, Lagos University Teaching Hospital, Lagos, Nigeria
}

\begin{abstract}
Background: Infertility remains a threat to successful reproduction by couples desirous of pregnancy.

Objective: To determine the pattern of infertility cases amongst infertile couples seeking care in Lagos University Teaching Hospital as well as challenges in their management.

Methods: A review of the management of couples referred for infertility to the gynaecological outpatient clinic of the Lagos University Teaching Hospital (LUTH), Nigeria from $1^{\text {st }}$ January 2005 to $31^{\text {st }}$ December 2006.

Results: The incidence of infertility was found to be $26.8 \%$ of the gynaecological consultations with a mean duration of infertility of $4.3 \pm 3.4$ years. The mean age of the women was $33.8 \pm 5.2$ years and $66.1 \%$ were nulliparous. Secondary infertility accounted for $80 \%$ of cases. Male factors only was the cause in $11.1 \%$, female factor only in $37.8 \%$, both male and female factors in $40 \%$ while no cause was identifiable in $11.1 \%$. There was no association between tubal occlusion and a history of induced abortion in this study $(\mathrm{p}>0.05)$. There was a high rate of discontinuation of care by their large numbers lost to follow up.

Conclusion: Infertility is still a public health problem in Lagos, Nigeria.

Key words: Infertility pattern: causes, incidence, outcome and challenges in care

African Health Sciences 2013; 13(4): 1126 - 1129 http://dx.doi.org/10.4314/ahs.v13i4.37
\end{abstract}

\section{Introduction}

Infertility is defined as the inability of a couple to conceive after one year of regular unprotected intercourse. ${ }^{1}$ It can be further classified into primary infertility, in which no previous pregnancies have occurred and secondary infertility in which prior pregnancy, although not necessarily a live birth, has occurred. ${ }^{2}$ One of the greatest desires of couples is successful reproduction especially in the developing countries. Infertility thus causes severe emotional and social distress for the couple especially the social stigma attached to it in Africa. ${ }^{3}$

Conception is expected to occur in $84 \%$ of women having regular unprotected intercourse within 12 months and in $92 \%$ within 24 months. ${ }^{4}$ It is estimated that as many as 80 million couples are affected by infertility worldwide. ${ }^{5}$ The incidence of infertility varies for different population studied, data from population based studies suggest that $10-15 \%$

\footnotetext{
*Corresponding author:

Dr. Omololu Adegbola

Department of Obstetrics \& Gynaecology

College of Medicine, University of Lagos/

Lagos University Teaching Hospital

PMB 12003, Lagos

Nigeria

Phone number + (234) 802-322-5033

E-mail: omololuadegbola@gmail.com
}

of couples in the western world experience infertility. ${ }^{6}$ There is paucity of national vital statistics in Nigeria and hospital based studies constitute the main sources of information. However, it is by far the commonest presenting complaint in gynaecological clinics with prevalence of $14.8 \%$ to $38.8 \%$ of outpatient gynaecological consultation has been reported. ${ }^{7,8}$

The World Health Organization (WHO) had stated that where there is an infertility rate exceeding $15 \%$ of couples, it should be recognized as a public health problem. ${ }^{5}$ While primary infertility is higher in other regions of the world, secondary infertility is more common in Afrcia. ${ }^{3,9}$ This had been reported as sequel to poorly managed pelvic inflammatory disease, resulting in utero-tubal damage and or pelvic adhesions. ${ }^{9}$ Also causes of infertility varies from population to population and is influenced by sociocultural differences, degree of promiscuity, prevalence of sexually transmitted infection and reproductive health behaviour. ${ }^{7}$

The most common cause of infertility in our environment is tubal disease which is attributed to infection either post abortally or are sexually transmitted. 3,10 Though knowledge about infertility is ever increasing daily, continued appraisal is necessary so that local data can be generated which 
would be useful in counseling, investigation, management of these couples as well as help in proper and adequate health care plan for this part of the world.

\section{Methods}

This was a cross sectional study involving couples that presented with infertility at the gynaecological outpatient clinic of the Lagos University Teaching Hospital (LUTH), Nigeria for the first time from $1^{\text {st }}$ January 2005 to $31^{\text {st }}$ December 2006. They were evaluated and followed up till $31^{\text {st }}$ December 2008 when the study ended.

Only data from couples with inability to conceive after one year of regular unprotected coitus were analyzed and presented in this study. Relevant data noted included age, parity, duration of infertility, history of induced abortions, results of ovulation tests, results of seminal fluid analysis, tubal patency test as well as treatment given and outcome of management. In LUTH, Human Immunodeficiency Virus (HIV) status is not routinely assayed for, in couples seeking infertility management except there is clinical evidence suggestive of immunodeficiency and as such the HIV status of the clients was not ascertained.

Ovulation was assessed by mid luteal phase progesterone. Other hormones measured at the mid luteal phase included prolactin, oestradiol, follicle stimulating hormone and luteinizing hormone. Thyroid function test was done when there was clinical evidence of thyroid dysfunction. Male factor assessment was based on seminal fluid analysis. At least two seminal fluid analysis result done at least 4 of 6 weeks apart and the criteria used was that of the World Health Organization (WHO) as contained in the manual on human sperms. ${ }^{11}$ The study was in accordance with the ethical standard of the Lagos University Teaching Hospital, Nigeria. A patient was said to be lost to follow up if not seen again at the outpatient clinic for six months from the last visit. The statistical analysis was performed using Epi-Info. A p value of $<0.05$ was considered significant.

\section{Results}

There were 2724 new patients that presented at the gynaecological outpatient clinic during the study period. Seven hundred and thirty of them were cases of infertility, thus giving an incidence of $26.8 \%$. Of the 730 cases, 404 (55.3\%) case notes could be retrieved from the medical records department and these were the ones analyzed. One hundred and forty
(34.7\%) of these 404 absconded after the first initial visit and never returned for follow up thereafter. Of the $264(65.3 \%)$ patients who continued, 13 $(4.9 \%)$ were able to achieve pregnancy, $2(0.7 \%)$ were referred to centers with facilities for assisted conception, $39(14.8 \%)$ were still attending the gynecological clinic for follow up while $210(79.5 \%)$ were lost to follow up, that is not seen 6 months from the last visit as at $31^{\text {st }}$ December 2008 when the study ended.

Ninety (34.1\%) of the 264 couples had the three basic investigations done (tubal patency test, seminal fluid analysis and hormonal assay). The others had one, two or no investigations done for reasons ranging from financial constraint, husbands refusing to do seminal fluid analysis and other reasons best known to the couples.

Of the 404 women whose case records could be retrieved, the mean age was $33.8 \pm 5.2$ years (range 20-49 years) with $365(90.4 \%)$ of low parity ( 0 and $1)$ as shown in table $I$. The mean duration of infertility was $4.3 \pm 3.4$ years (range $1-25$ years) with the duration of infertility highlighted in table 2 . Three hundred and twenty three $(80 \%)$ were cases of secondary infertility while $81(20 \%)$ were cases of primary infertility.

Table 1: Parity distribution of infertile patients

\begin{tabular}{lll}
\hline Parity & Frequency & Percentage \\
\hline 0 & 267 & 66.1 \\
1 & 98 & 24.3 \\
2 & 31 & 7.7 \\
3 & 7 & 1.7 \\
4 & 1 & 0.2 \\
Total & 404 & 100.0 \\
\hline
\end{tabular}

Table 2: Duration of infertility

\begin{tabular}{lll}
\hline $\begin{array}{l}\text { Duration } \\
\text { (years) }\end{array}$ & Frequency & Percentage \\
\hline $1-5$ & 297 & 73.5 \\
$6-10$ & 81 & 20.1 \\
$11-15$ & 24 & 6.0 \\
$16-20$ & 1 & 0.2 \\
$21-25$ & 1 & 0.2 \\
Total & 404 & 100.0 \\
\hline
\end{tabular}

Mean $4.3+3.4$ years

Among the 90 couples that completed the three basic investigations, male factor was solely the cause of infertility in 10 (11.1\%); female factor only in 34 
(37.8\%); both male and female factors in $36(40 \%)$ and no identifiable causes in $10(11.1 \%)$ couples. Out of the 34 couples with female factor only infertility, $8(23.5 \%)$ had tubal factor as the cause, $11(32.4 \%)$ was as a result of hormonal abnormalities while the remaining $15(44.1 \%)$ was as a result of a combination of tubal, hormonal and uterine abnormalities.

Of the 179 women who had hysterosalpingography done sixty eight had tubal occlusion (either unilateral in 27 cases or bilateral in 41 cases) of which 42 had at least one previous history of induced abortion. One hundred and eleven had bilateral tubal patency, out of which 52 had a history of at least one previous induced abortion. This was however not statistically significant $(p>$ 0.05).

Of the 152 women who had hormonal assay, $62(40.8 \%)$ was normal, $50(32.8 \%)$ had hyperprolactinaemia only, $20(13.2 \%)$ had anovulation unrelated to hyperprolactinaemia (evidenced by low midluteal progesterone and normal prolactin level), $14(9.2 \%)$ had hormonal assay suggestive of polycystic ovarian syndrome while $6(4 \%)$ had pattern suggestive of premature ovarian failure.

Of the total of 148 men that had seminal fluid analysis, $69(46.6 \%)$ were normal, 48 (32.4\%) had oligospermia, 9 (6.1\%) had oligospermia and asthenozoospermia, $17 \quad(11.5 \%)$ had asthenozoospermia while $5(3.4 \%)$ had azoospermia.

Of the 264 couples who were followed up, they were treated based on the identified aetiological causes with ovulation induction with clomiphene citrate and use of dopaminergic drugs like bromocriptine being the commonest treatment offered for anovulation and hyperprolactineamia respectively.

\section{Discussion}

The incidence rate of $26.8 \%$ found in this study is higher than $14.8 \%$ quoted in a similar study done in southwestern Nigeria. ${ }^{7}$ It is also higher than $10 \%$ $15 \%$ of couples in the western world that was reported to experience infertility. ${ }^{6}$

The mean duration of infertility before presentation was $4.3 \pm 3.4$ years. This is slightly higher than the mean duration of $3.38 \pm 1.65$ years in one study, ${ }^{7}$ but lower than $7.5 \pm 6.0$ years in yet another study. ${ }^{9}$ The difference might be due to socio-cultural factors in different regions of the country as well as the fact that couples with infertility do not seek specialist care first. They would rather present first to general practitioners, wait passively or seek unorthodox care like traditional medical practitioners or healers before presenting to a specialist.

The mean age of the women at presentation was $33.8 \pm 5.2$ years. This was higher than $28.3 \pm 6.0$ years in a study ${ }^{9}$ which can be attributed to cultural differences in age at marriage. Secondary infertility occurred in as high as $80 \%$ of couples in this study which is similar to other studies where secondary infertility accounted for $63.3 \%{ }^{9}$ and $78.3 \%{ }^{7}$ respectively. This is different from the western world experience where incidence of primary and secondary infertility is almost at per at $50 \%$ each. ${ }^{6}$

Male factor accounted for $11.1 \%$, female factor $37.8 \%$, unexplained infertility for $11.1 \%$, while a combination of male and female factors accounted for $40 \%$ of cases. This result is different from the study done in the Northern part of the same country where female factor solely accounted for $31.3 \%$ and was the commonest cause, male factor only $28.6 \%$, both partners in $30.0 \%$ and in $7.9 \%$ it was unexplained while in $2.2 \%$ spontaneous pregnancy occurred during the period of investigations.

It is also different from another study done in the southern part of the country where female factor only was the commonest cause and accounted for $51.8 \%$, male factor only $26.8 \%$ and both partners in $21.4 \% .^{7}$ It is also equally different from the pattern described in the western world where it has been noted that male partners are directly responsible for $25 \%$ of causes of infertility and is thought to play a contributory role in another $25 \% .{ }^{6}$ The difference might be due to environmental factors like stress which can affect ovulation, exposure to toxins which can affect both male and female fertility and sexually transmitted infections. Exposure to these factors varies among different communities.

Fifteen $(44.1 \%)$ of the couples that had female factors only infertility had a combination of hormonal, uterine abnormalities and tubal occlusion, while $11(32.4 \%)$ were due to hormonal abnormalities alone and $8(23.5 \%)$ were as a result of tubal occlusion. Uterine factor was not solely responsible for female factor infertility in this study. This differs from another study in the northern part of the same country where tubal occlusion accounted for as high as $63.6 \%$ of the female factor infertility. ${ }^{8}$ This difference might be attributed to the fact that Lagos, being an urban centre has higher safe abortion practices, awareness about prevention and prompt treatment of infection. ${ }^{12}$ This may also explain the finding in this study showing no association between 
tubal occlusion and history of induced abortion.

Hyperprolactinaemia was the commonest hormonal abnormalities in this study which is in agreement with an earlier study done in Lagos. ${ }^{13}$ Sixty nine $(46.6 \%)$ of the male partners had

normal seminal fluid parameter which was slightly lower than that found in another study where 51.8\% had normal seminal fluid parameter. ${ }^{7}$

The fact that $326(44.7 \%)$ case records could not be retrieved gives cause for concern. This indicate poor record keeping in the institution and is a pointer to the fact that there is a need to shift from the paper records to electronic records to avoid loss of information in the future. These lost case records may have altered the findings in this study if available for analysis and as such serves as a limitation to this study.

The high lost to follow up may be due to the fact that infertility investigation is quite expensive especially the hormone assays, poor medical insurance coverage and very few of these insurance providers are willing to bear the cost of such investigations. The high attrition rate shown by the number of patients lost to follow up may possibly suggest that most of the patients "doctor shop" by going from one care providers to another hoping to get cheaper treatment options. This only emphasizes the fact that there is an urgent need for public enlightenment on the causes and management of infertility, adequate counseling and emotional support for the couple as well as effective communication with them about every management decision would go a long way to reduce this. There is also a need for comprehensive health insurance scheme which should also take care of infertility management.

\section{Conclusion}

The incidence of infertility in this study, going by the WHO criteria, shows that infertility is still of significant public health concern in our environment. Although it is a disorder of the couple, hormonal abnormalities, which may be modifiable by lifestyle changes as well as medications, have been noted in the females.

\section{References}

1. Hammadieh N, Olufowobi O, Afnan M, Sharif $\mathrm{K}$. Factors affecting the outcome of in vitro fertilization treatment. In: Studd J, (ed) Progress in Obstetrics and Gynaecology Vol. 16. Elsevier
Science Limited: London: 2005: 259-273.

2. Yao MWH, Schust DJ. Infertility. In: Berek J. S., (ed) Novak's Gynaecology $13^{\text {th }}$ ed. Lippincott William and Wilkin: 2002: 973-1066.

3. Gerais A. S., Rushwan H. Infertility in Africa. Popul. Sci 1992; 12: 25-46.

4. te Velde ER, Eijkemans R, Habbema HDF. Variation in couple fecundity and time to pregnancy, an essential concept in human reproduction. Lancet 2000; 355: 1928-1929.

5. Bergstrom S. Childlessness. In: Lawson J. B., Harrison K. A., Bergstrom S, (eds) Maternity care in developing countries RCOG PRESS: 2001: 360-368.

6. Bhattacharya S. Infertility. In: Edmonds D. K. (ed) Dewhurts's Textbook of Obstetrics and Gynaecology $7^{\text {th }}$ ed. Blackwell Publishers. Oxford University Press: 2007: 440-460.

7. Olatunji AO, Sule-Odu AO. The Pattern of Infertility Cases at a University Hospital. West Afr J Med 2003; 22 (3): 205-207.

8. Idrisa A, Ojiyi E. Pattern of Infertility in NorthEastern Nigeria. Trop J Obstet Gynaeol 2000; 17 (1): 27-29.

9. Audu BM, Massa AA, Bukar M. Clinical Presentation of Infertility in Gombe, NorthEastern Nigeria. Trop J Obstet Gynaecol 2003; 20 (2): 93-96.

10. Giwa-Osagie OF, Ogunyemi D, Emuveyan E.E.et al. Aetiologic classification and sociomedical characteristics of infertility in 250 couples. Int J Fert 1984;29 (2): 104-108.

11. World Health Organization (WHO). Laboratory manual for the examination of human semen and sperm mucus interaction. $3^{\text {rd }}$ edition. Cambridge University Press. 1992.

12. Bankole A, Oye-Adeniran BA, Singh S. et al. Unwanted pregnancy and induced abortion in Nigeria: Causes and Consequences. New York: Guttmacher Institute 2006: 1-32.

13. Kuku SF, Akinyanju PA, Ojeifo JO. Serum levels of gonadotropins, prolactin and progesterone in infertile female Africans. Int J. Fertil 1987; 32 (5): 393-398. 